\title{
Valorization of Grape by-Products
}

\section{Cristina Damian*, Ana Olteanu, Mircea Oroian, Ana Leahu, Sorina Ropciuc}

Stefan cel Mare University of Suceava, Faculty of Food Engineering, 13 Universitatii, Suceava, Romania

Email address:

cristinadamian@fia.usv.ro (C. Damian)

To cite this article:

Cristina Damian, Ana Olteanu, Mircea Oroian, Ana Leahu, Sorina Ropciuc. Valorization of Grape by-Products. American Journal of Environmental Protection. Vol. 4, No. 3, 2015, pp. 134-138. doi: 10.11648/j.ajep.20150403.14

\begin{abstract}
The by-products of processed grape (grape seeds and grape peels) can be recovered for further food applications. Extracts of grape by-products were obtained with solvents of different polarity (aqueous acetone, methanol and ethanol) and assayed for their total phenolic content and antioxidant activity. The high amount of total phenols was found in grape seeds. Higher yields of phenolic antioxidants were recovered with acetone. The recovery of phenolic antioxidants from the peels and seeds of processed grape could be a valuable alternative to traditional disposal routes (including landfill), in particular for cooking grape varieties. The recycling process could enhance the growth of traditional culinary markets thanks to the new business opportunities for the peel-derived and seed-derived materials.
\end{abstract}

Keywords: Waste Valorisation, Peel and Seeds Polyphenols, Antioxidant Value

\section{Introduction}

The agricultural sector produces a large amount of byproducts and wastes, representing an increasing interest as industrial crops both due to the economic reasons and from the environmental concerns.

Grapes (Vitis vinifera) belong to Vitaceae family. There are many reports on the benefits of eating grapes as they are known to be packed with nutrients such as magnesium, vitamins (A, B1, B2, B6 and $\mathrm{C}$ ) and possess antioxidants properties. Grapes are effective as anti-ageing agents through the effects of resveratrol, a molecule in the skin pulp [AHMAD, W., 2014].

The grape is one of the major fruit crops worldwide and its harvest is about 60 millions tones per year [LAFKA, T.I., 2007]. About $80 \%$ of the harvest is utilized for winemaking and the grape waste is about $20 \%$ of the weight of processed grapes [MAZZA, G., 1993]. Grape pomace consists in the skin, stems and seeds of grapes that remain after processing in the wine and juice industry [MUŇOZ-GONZÁLES, C., 2013]. Grape processing wastes can be an important economical problem to producers besides the environmental impact caused by the large amount of these types of residues generated during the harvest season. The majority of this pomace is discarded as natural waste or distilled to produce alcohol and other distilled beverages. Therefore, the wineries will have new economic difficulties with winery waste management.
Some traditional applications of grape pomace are for animal feed formulations or compost production, without any pre-treatment. Recently, the scientific works carried out on the characterization of the chemical components of grape waste by-products have allowed looking for different applications in trying to obtain high added value ingredients. Some of these applications are the production of grape-seed oil [FIORI, L., 2007] or biodesel from it [FERNÁNDEZ, C.M., 2010], obtaining dietary fibre [IGARTUBURU, J.M., 1998] and the extraction of polyphenols with antioxidant properties [PINELO, M., 2005].

Marcs, stems and dregs (sludgy residual deposits at the bottom of fermentation vats) represent sources of antioxidants that have been relatively unexploited to date, but are of increasing industrial interests. If stalks are stripped from grape prior to crushing, winery marc consists of approximately $30 \%$ seeds and $70 \%$ skin and pulp. Studies on grape seeds are rather limited, despite their richness in polyphenolic substances, mainly monomeric and oligomericflavanols [TOUNSI, M.S., 2009]. Phenolic compounds have received considerable attention due to their pharmacological effects, including antimicrobial and antioxidant activities [DELIORMANORHAN, D., 2009]. Alternatively, polyphenols from grape pomaces are suggested to be a valuable crop for the production of adhesives [MENDES, J.A.S., 2013]. There are different efficient 
detection methods [RZEPECKA-STOJKO, A., 2010].

In recent years, antioxidants have gained more importance because of their positive involvement as health promoters in conditions such as cardiovascular problems, atherosclerosis, treatment of many forms of cancer, and the ageing process. Many antioxidants compounds, naturally occurring in plant sources have been identified as free radical scavengers [DUH, P.D., 1998]. Nowadays, interest has considerably increased in finding naturally occurring antioxidants for use in food or medicinal materials to replace synthetic antioxidants, which are being restricted due to their side effects such as carcinogenity [ZHENG, W., 2001, HABEEBULLAH, S.F.K., 2010]. Natural antioxidants are required at higher level than artificial products, so the importance of identifying active components and optimizing usage is emphasized [MOHAMED, H.M.A.,].

The antioxidant activity may be determined using different free radicals. One of the methods use DPPH or 1,1-diphenyl2-picrylhydrazyl, which as radical is violet and in reduced form is yellow. The reduction is made with antioxidants and the color variation is used to evaluate the antioxidant concentration needed to reduce a certain amount of radicals. Spectrophotometric measurements can determine the color variation [SÁNCHEZ-MORENO, C., 2002].

$$
\begin{array}{rr}
\text { DPPH } \stackrel{\text { antioxidant }}{\longrightarrow} \mathrm{DPPH}-\mathrm{H} \\
\text { Violet } & \text { Yellow }
\end{array}
$$

$$
\text { Figure1. DPPH method scheme. }
$$

The utilization of by-products from winemaking is an urged problem in Europe within context of recently posed regulations presuming measures against burying of wine byproducts affecting the soil erosion/compaction and the quality of groundwater [CCE, 2006].

In the present investigation, phenolic content of seed and peel methanolic, ethanolic and aqueous acetone extracts of Vitisvinifera (Babeasca, Fraguta, and Tamaioasa) were investigated by spectrophotometry. Antioxidants activity against DPPH radical of these extracts were assayed too.

\section{Materials and Methodology}

\subsection{Chemicals}

DPPH (1,1-diphenyl-2-picrylhydrazyl) and FolinCiocalteau reagent were purchased from Aldrich. These solutions were wrapped in aluminium foil and stored at $40 \mathrm{C}$. All other chemicals used were of analytical grade.

\subsection{Plant Material}

Our study was carried out on rape seeds and peels of grape of three varieties (Vitis vinifera L.) Babeasca (red grape), Fraguta (rosé grape) and Tamaioasa (white grape). $1 \mathrm{~kg}$ of samples has been harvested, dating from September 2013, from the local market. Seeds and peels were manually separated and dried at ambient temperature in dark until used.

\subsection{Polyphenol Extraction}

The air-dried seeds and peels were ground. $1 \mathrm{~g}$ of this ground material was extracted by stirring with $10 \mathrm{~mL}$ of pure methanol, ethanol and aqueous acetone for $30 \mathrm{~min}$. The extracts were then kept for $24 \mathrm{~h}$ at $40 \mathrm{C}$, filtered through a Whatman No4 filter paper, and evaporated under vacuum to dryness and stored at $4^{0} \mathrm{C}$ until analyzed [MAU, J.L., 2001].

\subsection{Total Phenolic Content}

Total phenolic contents were assayed using the FolinCiocalteau reagent, following Singleton's method slightly modified by Dewanto et al. [DEWANTO, V., 2002]. An aliquot $(0.125 \mathrm{~mL})$ of a suitable diluted methanolic, ethanolic and aqueous acetone seed and peel extract ( $0.25 \mathrm{mg} . \mathrm{mL}-1)$ was added to $0.5 \mathrm{~mL}$ of deionized water and $0.125 \mathrm{~mL}$ of the Folin-Ciocalteau reagent. The mixture was shaken and allowed to stand for $6 \mathrm{~min}$, before adding $1.25 \mathrm{~mL}$ of $7 \%$ $\mathrm{Na}_{2} \mathrm{CO}_{3}$ solution. The solution was then adjusted with deionized water to a final volume of $3 \mathrm{~mL}$ and mixed thoroughly. After incubation for $90 \mathrm{~min}$ at $230 \mathrm{C}$, the absorbance versus prepared blank was read at $760 \mathrm{~nm}$. The phenolic content of seeds and peels (three replicates per treatment) was expressed as mg gallic acid equivalents (GAE) per gram of dry weight through the calibration curve with gallic acid. The calibration curve range was $50-400 \mathrm{mg} \cdot \mathrm{mL}^{-1}$ $\left(\mathrm{R}^{2}=0.99\right)$.

\subsection{DPPH Assay}

The electron donation ability of the obtained methanol, ethanol and aqueous acetone extracts was measured by bleaching of the purple-colored solution of 1,1-diphenyl-2picrylhydrazyl radical (DPPH) according to the method of Hanato et al. [HANATO, T., 1988]. $2 \mathrm{~mL}$ of methanolic grape seed and peel extracts were added to a $0.5 \mathrm{~mL}$ of a 0.2 mmol.L-1 DPPHmethanolic solution. The mixture was shaken vigorously and left standing at room temperature for $30 \mathrm{~min}$. The absorbance of the resulting solution was then measured at $517 \mathrm{~nm}$ after $30 \mathrm{~min}$. The antiradical activity (three replicates per treatment) was expressed as IC50 (mg.mL-1), the concentration required to cause a 50\% DPPH inhibition. A lower IC50 value corresponds to a higher antioxidant activity of seed and peel extract. The ability to scavenge the DPPH radical was calculated using the following equation:

$$
\text { DPPHscavengingeffect }(\%)=\left[\frac{\left(A_{0}-A_{1}\right)}{A_{0}}\right] \times 100
$$

where $A_{0}$ is the absorbance of the control at $30 \mathrm{~min}$, and $A_{l}$ is the absorbance of the sample at $30 \mathrm{~min}$. Samples were analyzed in triplicate.

\subsection{Statistics}

Samples were assayed in triplicate and results are given as averages \pm SD. Student's $t$ test was used for the statistical evaluation and $p<0.05$ was considered statistically significant. 


\section{Result and Discussion}

\subsection{Total Phenolics Contents}

Based on the absorbance values of methanolic extract solutions reacted with the Folin-Ciocalteau reagent and compared with the standard solutions of gallic acid equivalents, the total phenolic content is given in Figure 2. The phenolic content of seed extracts varied between varieties and ranged from 134.88 to $413.88 \mathrm{mg}$.GAE- 1 . Babeasca seeds have a higher phenolic amount (413.88 mg.GAE/g) than Fraguta ones (267.53 mg.GAE/g). Tamaioasa seeds presented only $134.88 \mathrm{mg} . \mathrm{GAE} / \mathrm{g}$.

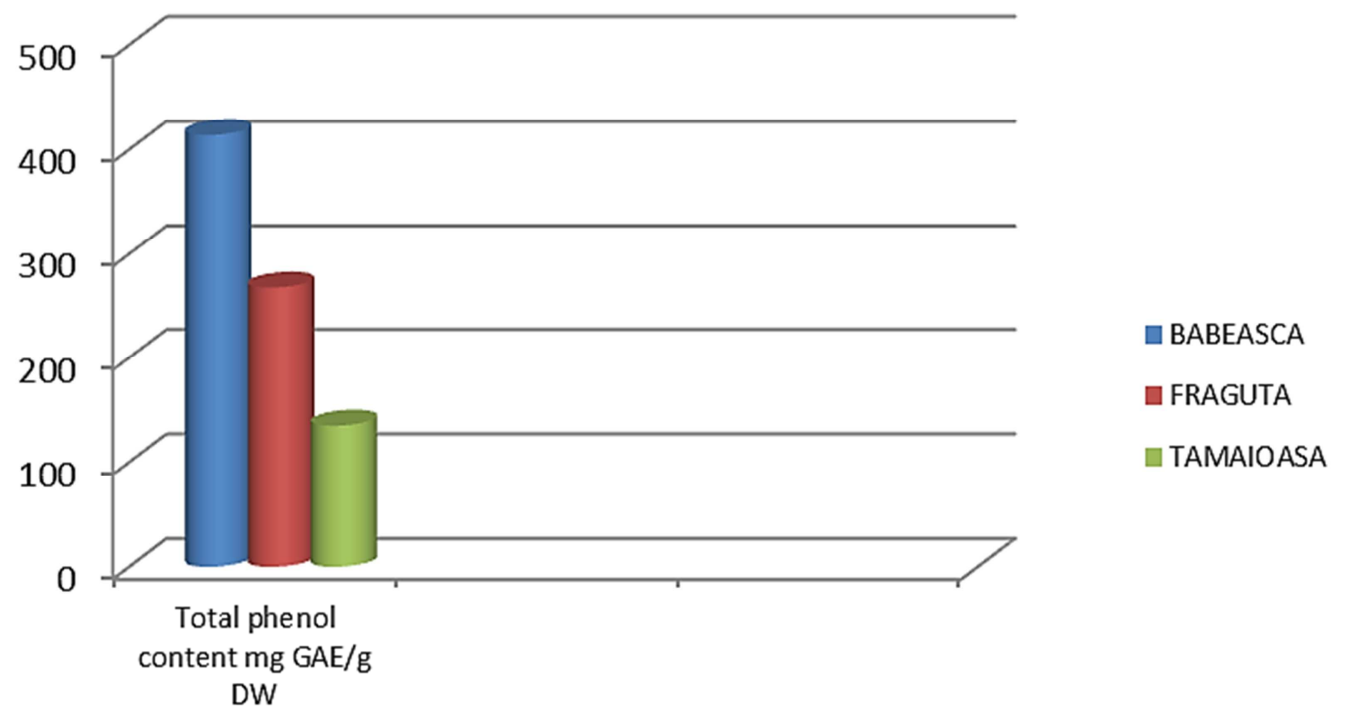

Figure 2. Total phenolic content in methanolic extracts from Babeasca, Fraguta and Tamaioasa seeds (mg gallic acid equivalents (GAE) per gram of dry weight).

Our results were different to those of Berrin et al. (2008) who mentioned the presence of moderate phenol amounts (88.11-105.7 mg.GAE/g DW) of four international varieties from Turkish Vitis vinifera seeds. However, Nilgün et al. (2004) noted that total phenolic content in seeds of Vitis vinifera L. species can reach $667.98 \mathrm{mg}$.GAE/g DW. These variations in total phenol content could be due to the various factors. One such factor may be the genetic potential of individual species for polyphenol biosynthesis [TOUNSI, M.S., 2009]. Apart from the genetic (varietal) background, maturation stage may also be critical in this respect $[\mathrm{DE}$
FREITAS, V.A.P., 1999]. It was observed that amounts of all seed polyphenols in grape decline considerably, and this fact was attributed to an initiation of oxidative phenomena, which appeared to follow second order kinetics [KENNEDY, J.A., 2000].

Winery waste was ground before extraction in order to reduce particle size and increase the yield of extracted phenols and their antioxidant activities. Ethanol gave extracts with lower phenol content than those of methanol. Extraction with aqueous acetone gave a yield of $43.5 \%$, compared to extraction with methanol.

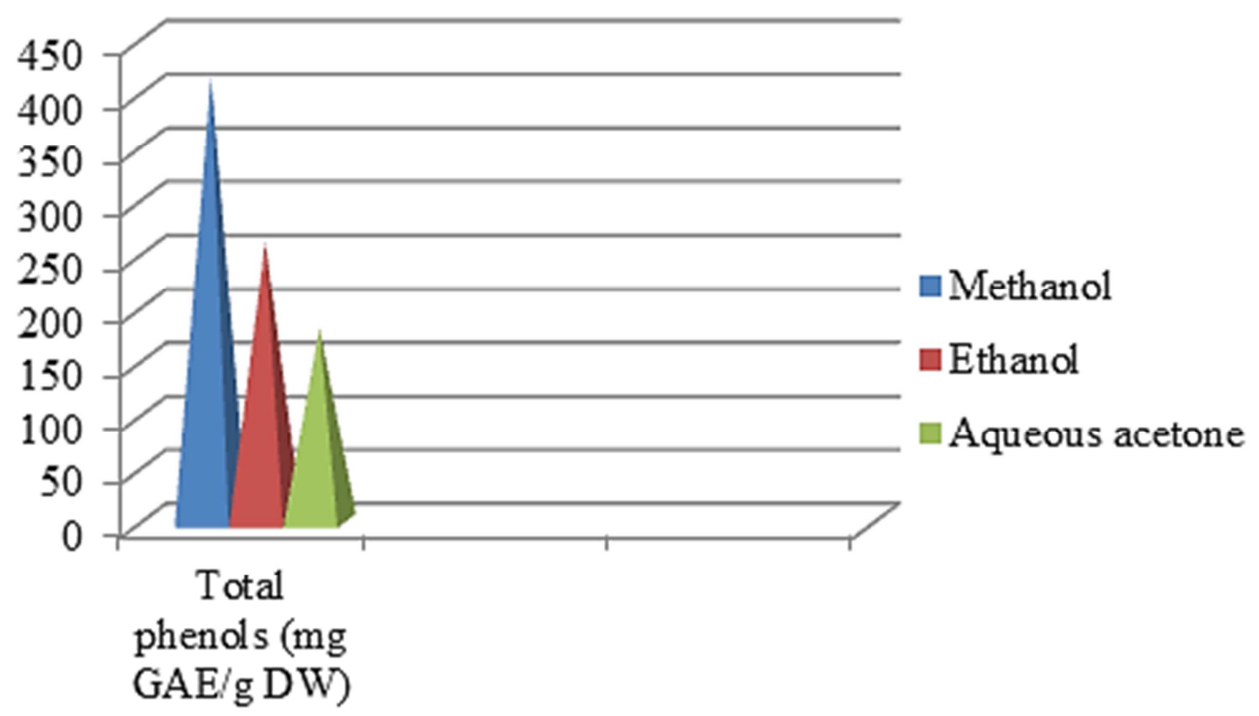

Figure 3. The effect of solvent on the quantity of extracted phenols from Babeasca winery waste. 


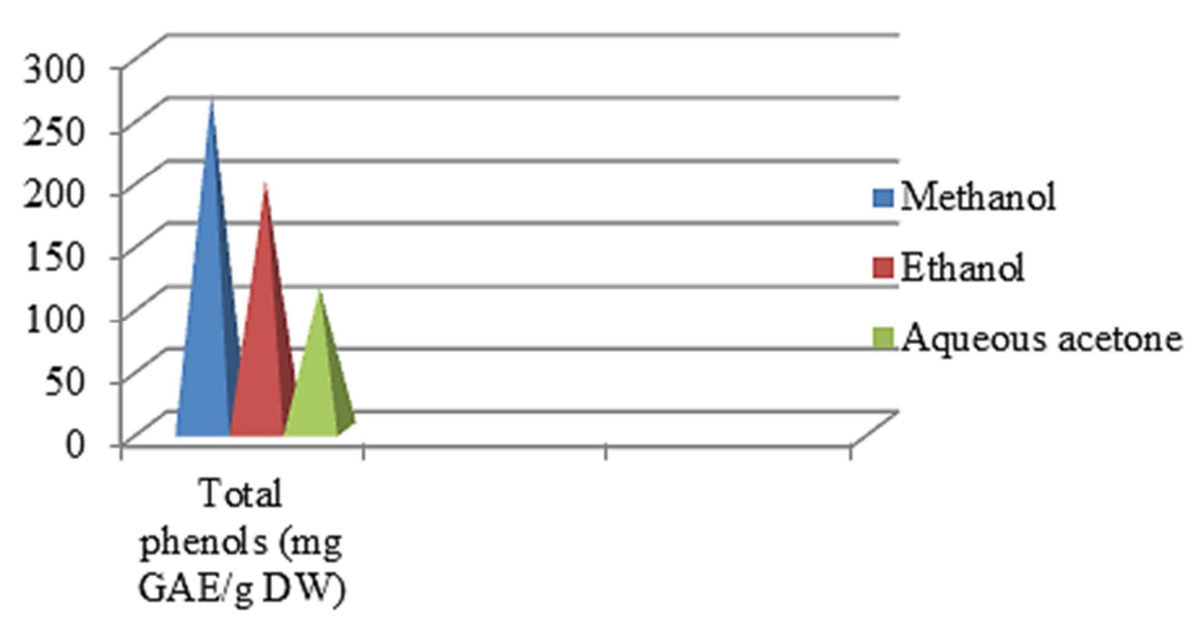

Figure 4. The effect of solvent on the quantity of extracted phenols from Fraguta winery waste.

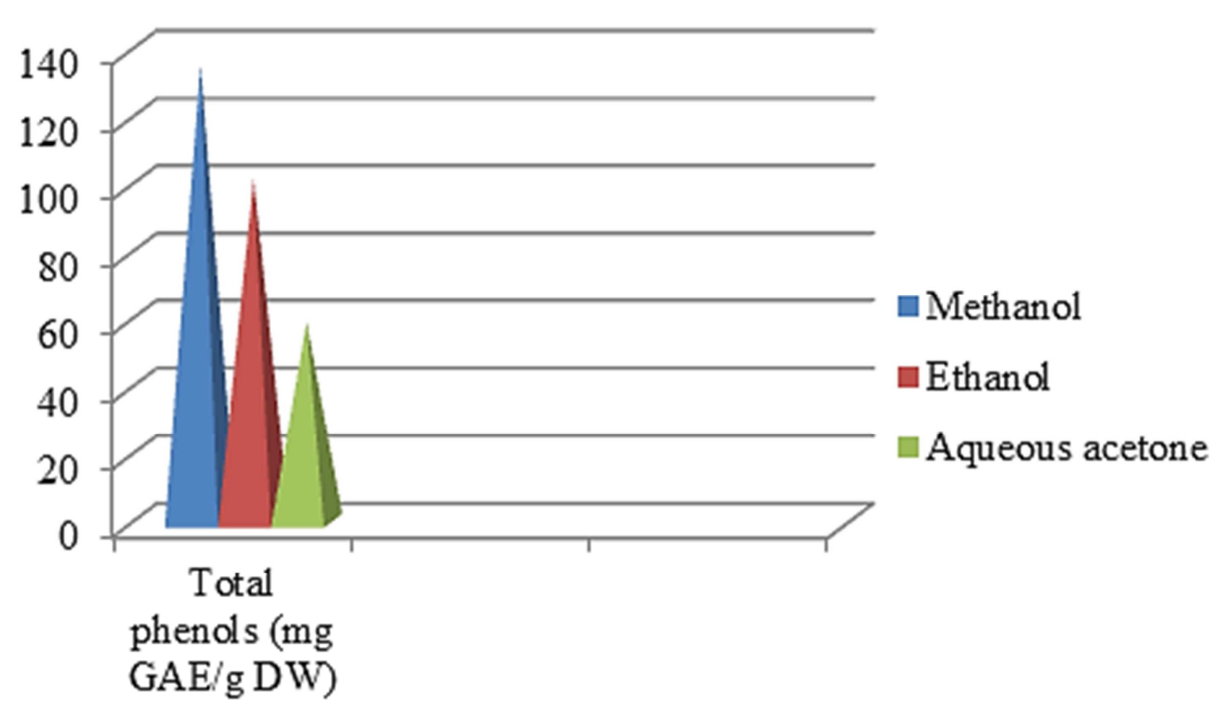

Figure 5. The effect of solvent on the quantity of extracted phenols from Tamaioasa winery waste.

\subsection{Antioxidant Activity}

The assessment of antioxidant activity showed that the examined seeds and peels were able to scavenge this radical (Table 1). Tamaioasa seeds displayed the highest activity compared to Fraguta seeds and Tamaioasa seeds (IC50 values were: $2.8,7.9$ and $27 \mu \mathrm{g} / \mathrm{mL}$, respectively). The synergic effect of the antioxidants in the extracts should be considered. The values of IC50 for the grape peels show that are no significant differences between Babeasca, Fraguta and Tamaioasa.

Table 1. Antiradical activity (DPPH) of Babeasca, Fraguta and Tamaioasa seeds and peels.

\begin{tabular}{ll}
\hline Samples & IC50 $(\mu \mathrm{g} / \mathbf{m L}) \mathbf{D P P H}$ \\
\hline Babeasca seeds & $2.8 \pm 0.12$ \\
Fraguta seeds & $7.9 \pm 0.67$ \\
Tamaioasa seeds & $27 \pm 0.33$ \\
Babeasca peels & $1.096 \pm 1.11$ \\
Fraguta peels & $1.107 \pm 2.87$ \\
Tamaioasa peels & $1.088 \pm 1.65$ \\
\hline
\end{tabular}

Values are means \pm standard deviation, $n=3$
A good correlation was found for the total polyphenols and DPPH method $(r=0.87)$. Although researchers often reached different conclusions, the issue of relation of the antioxidant activity and the concentration of polyphenolic compounds in foods has been repeatedly undertaken in the literature. Some did not discover the correlation between polyphenol content and the antioxidant activity of plant extracts while others showed a strong relationship between them [MARKOWSKI, J., 1998, WILL, F., 2008].

\section{Conclusion}

The results of this work indicate the presence of compounds possessing high antioxidant activity in grape seeds and peels (Vitis vinifera L.). In addition, the obtained results showed large differences found among the varieties in relation to the polyphenol content.

The present study provides data for supporting the use of Babeasca, Fraguta and Tamaioasa seeds and peels as natural antioxidant agents, and confirms that these extracts represent a significant source of phenolic compounds. 


\section{References}

[1] Ahmad, W., Khan, M.I., Waqar, M., Khan, M.A., Khan, A., Ramazan, R., Wali, S., Ahmad, F., Khan, N., Yousaf, S., Zeb, M., Khan, A.U., Rahman, M.U., Faisal, S., In vitro antibacterial activity of vitis vinifera leaf extracts against some pathogenic bacterial strains, Advances in biological research, 8(2), 2014, 62-67.

[2] Cce, comissão das comunidadeseuropeias. Para um sector vitivinícolasustentável. Comunicação da comissãoaoconselho e aoparlamentoeuropeu (pt), 319, Bruxelles.

[3] De freitas, V.A.P., Glories, Y., Concentration and compositional changes of procyanidins in grape seeds and skin of vitisvinifera varieties, J sci food agric, 79, 1999, 16011606.

[4] Deliormanorhan, D., Orhan, N., Özçelik, B., Ergun, F., Biological activities of vitis vinifera 1 . Leaves, Turk $\mathrm{j}$ biol, 33 , 2009, 311-348.

[5] Dewanto, V., Wu, X., Adom, K., Liu, R.H., Thermal processing enhancing the nutritional value of tomatoes by increasing total antioxidant activity, $\mathrm{J}$ agric food chem, 50, 2002, 3010-3014.

[6] Duh, P.D., Antioxidant activity of burdock (arctiumlappalinne): its scavenging effect on free radical and active oxygen, Jaocs, $75,1998,455-465$.

[7] Fernández, C.M., Ramos, M.J., Pérez, A., Rodríguez, J.F.,Production of biodiesel from winery waste: extraction, refining and transesterification of grape seed oil, Bioresourtechnol, 101, 2010, 7030-7035.

[8] Fiori, L., Grape seed oil supercritical extraction kinetic and solubility data: critical approach and modeling, J supercrit fluids, 43, 2007, 43-54.

[9] Habeebullah, S.F.K., Nielsen, N.S., Jacobsen, C., Antioxidant activity of potato peel extracts in a fish-rapeseed oil mixture and in oil-in-water emulsions, $\mathrm{J}$ am oil chemsoc, 87, 2010, 1319-1332.

[10] Hanato, T., Kagawa, H., Yasuhara, T., Okuda, T., Two new flavonoids and other constituents in licorice root: their relative astringency and radical scavenging effect, Chem pharm bull, 36, 1988, 1090-1097.

[11] Igartuburu, J.M., Pando, E., Rodríguez-Luis, F., Gil-Serrano, A., Structure of a hemicellulose $b$ fraction in dietary fiber from the seed of grape variety palomino (vitisvinifera cv. Palomino), J nat prod, 61, 1998, 881-886.

[12] Kennedy, J.A., Troup, G., Pilbrow, J.R., Hutton, D.R., Hewitt, D., Hunter, C.R., Ristic, R., Iland, P.G., Jones, G.P., Development of seed polyphenols in berries from vitis vinifera 1. Cv. Shiraz, Ajgwr, 6, 2000, 244-254.
[13] Lafka, T.I., Sinanoglou, V., Lazos, E.S., On the extraction and antioxidant activity of phenolic compounds from winery wastes, Food chemistry, 104, 2007, 1206-1214.

[14] Markowski, Jaroslaw, and Witold Plocharski. Determination of phenolic compounds in apples and processed apple products, Journal of fruit and ornamental plant research 14, 2006, 133-142.

[15] Mau, J.L., Chao, J.R., Wu, G.R., Wu, K.T., Antioxidant properties of methanolic extracts from several ear mushrooms, J agric food chem, 49, 2001, 5461-5467.

[16] Mazza, G., Miniati, E., 1993. Grapes. In anthocyanins in fruits, vegetables and grains, Bocaraton, Ann Harbor, London, Tokyo: CRC press, pp. 149-199.

[17] Mendes, J.A.S., Prozil, S.O., Evtuguin, D.V., Cruz Lopes, L.P., Towards comprehensive utilization of winemaking residues: characterization of grape skins from red grape pomaces of variety touriganacional, Industrial crops and products, 43, 2013, 25-32.

[18] Mohamed, H.M.A., Awatif, I.I., The use of sesame oil unsaponifiable matter as a natural antioxidant, Food chemistry, 1998, 62.3: 269-276.

[19] Muñoz-González, C., Rodríguez-Gencomo, J.J., MartínÁlvarez, P.J., Moreno-Arribas, M.V., Pozo-Bayón, M.Á. Recovery of aromatic aglycones from grape pomace winemaking by-products by using liquid-liquid and pressurized-liquid extraction, Food analytical methods 7.1, 2014, 47-57.

[20] Pinelo, M., Rubilar, M., Jerez, M., Sineiro, J., Núňez, M.J., Effect of solvent, temperature, and solvent-to-solid ratio on the total phenolic content and antiradical activity of extracts from different components of grape pomace, J agric food chem, 53, 2005, 2111-2117.

[21] Rzepecka-Stojko, A., Maciejewska-Paszek, I., Stec, M., Kurzeja, E., Kaska, A., Pawlowska-Góral, K., The influence of extraction method on obtaining polyphenolic compounds from bee pollen, Farmaceutycznyprzegladnaukowy, 7, issue 1, 2010, 38-41.

[22] Sánchez-Moreno, C., Review: methods used to evaluate the free radical scavenging activity in foods and biological systems, Food science and technology international, 8(3), 2002, 121-137.

[23] Tounsi, M.S., Ouerghemmi, I., Wannes, W.A., Ksouri, R., Zemni, H., Marzouk, B., Kchouk, M.E., Valorization of three varieties of grape, Industrial crops and products, 30, 2009, 292-296.

[24] Zheng, W., Wang, S.Y., Antioxidant activity and phenolic compounds in selected herbs, J agric food chem, 49, 2001, 5165-5170.

[25] Will, F., Roth, M., Olk, M., Ludwig, M., Dietrich, H., Processing and analytical characterisation of pulp-enriched cloudy apple juices. LWT-food science and technology 41.10, 2008, 2057-2063. 